\title{
Aeroelastic Analysis of Wings in the Transonic Regime: Planform's Influence on the Dynamic Instability
}

\author{
Mario Rosario Chiarelli and Salvatore Bonomo \\ DICI, University of Pisa, Largo Lucio Lazzarino 1, 56122 Pisa, Italy \\ Correspondence should be addressed to Mario Rosario Chiarelli; chiarelli@ing.unipi.it
}

Received 12 November 2015; Accepted 23 May 2016

Academic Editor: Hikmat Asadov

Copyright ( 2016 M. R. Chiarelli and S. Bonomo. This is an open access article distributed under the Creative Commons Attribution License, which permits unrestricted use, distribution, and reproduction in any medium, provided the original work is properly cited.

\begin{abstract}
This paper presents a study of transonic wings whose planform shape is curved. Using fluid structure interaction analyses, the dynamic instability conditions were investigated by including the effects of the transonic flow field around oscillating wings. To compare the dynamic aeroelastic characteristics of the curved wing configuration, numerical analyses were carried out on a conventional swept wing and on a curved planform wing. The results confirm that, for a curved planform wing, the dynamic instability condition occurs at higher flight speed if compared to a traditional swept wing with similar profiles, aspect ratio, angle of sweep at root, similar structural layout, and similar mass. A curved wing lifting system could thus improve the performances of future aircrafts.
\end{abstract}

\section{Introduction}

Modern technologies are aimed at increasing efficiency, in order to reduce operative costs and pollution and/or to increase the performances of aircrafts. For several years the Aerospace Engineering Unit of the Department of Civil and Industrial Engineering of the University of Pisa has been studying a novel geometry for wings with high aspect ratio. The wing has a curved planform: both the leading and trailing edges of the wing are described by curved lines. The in-plane curvature of the wing considerably reduces the aerodynamic drag especially in the transonic regime where the nonuniform distribution of the sweep angle of the curved wing leads to a reduction in the wave drag effects.

In the literature, various works focus on wing configurations with a curved leading edge or curved planform. The main topics discussed are a reduction in the induced drag or classical application of low aspect ratio wings for high supersonic configurations [1-5]. Only the authors in [2] discuss in detail the effects of a curved leading edge for a wing operating in the transonic regime; however, the trailing edge of the wing is assumed to be straight.

At the same time patents concerning the curved planform concept have been deposited, but only for a tip extension of wings of transport aircrafts $[6,7]$. It is well known that the wing tip of the B787 aircraft has not only an out-off plane "C" shape but also a curved planform [8].

To the best of our knowledge, there are no studies on a fully curved planform shape with high aspect ratio wings (with both the leading edge and the trailing edge curved). From an engineering point of view, the research interest in such a wing configuration particularly concerns the strong reduction in drag and the important reduction in structural weight. Both of these synergic effects could lead to significant reduction in fuel consumption and pollution.

In transonic flight conditions, the flow field on the wings is strongly nonlinear, which is why the theoretical modelling of realistic aircraft configurations represents a challenge for researchers. Often, the technical literature regards the validation procedures of numerical techniques, adopted to describe the aerodynamic performances of wings or aircrafts operating in the transonic regime. Several works try to represent pressure and lift distributions. In these cases often the numerical results agree very well with the experimental data [9-11]. On the other hand, if the objectives include a realistic estimation of the drag for wing models or for complete aircraft configurations, the research also requires a large amount of human and computational resources [12-14]. 


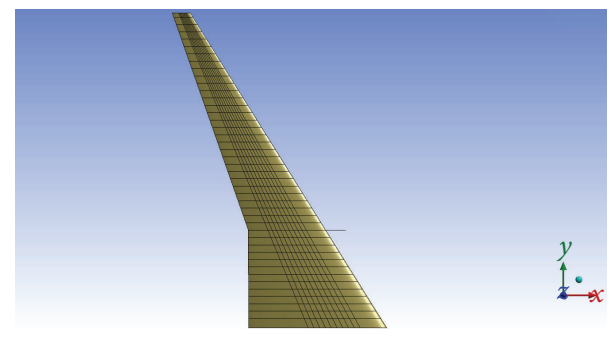

FIGURE 1: Swept wing model.

The present work compares the dynamic aeroelastic behaviour of wings, with different planform shapes, in a three-dimensional fully transonic flow field.

Today by means of a fluid structure interaction (FSI) technique, it is possible to represent the physics of transonic phenomena which develop around deformable lifting surfaces. There are several works that study the dynamic behaviour in the transonic regime of profiles mounted on elastic supports. However in these cases there are no threedimensional effects of the flow around a real wing. On the other hand, the dynamic oscillations of a three-dimensional lifting surface make the problem very complex. The analysis becomes more complicated if dynamic interactions arise between the transonic flow field and the structural response of the wings. Thus numerical results obtained by comparative analyses carried out with a well-structured procedure for the construction of the aerodynamic grids with a similar topology, a similar number of cells, and a similar layout of cell dimensions for the problems analysed can guarantee a reliable technical comparison of the physical behaviours of the wing configurations under observation without having to use prohibitive computational resources. This is also true if the absolute values of the computed technical coefficients are affected by modelling errors. In fact, in the case of structured and similar fluid dynamic grids, these errors will have the same quantitative effects. Thus several numerical activities have been carried out at the University of Pisa to compare the aerodynamic behaviour of a curved wing with that of a conventional swept wing.

The results of the studies on the drag reduction obtained with a curved wing configuration can be found in [15-20]. In these works a preliminary analysis carried out with the NASTRAN ${ }^{\circledR}$ code also showed that such curved wings have a good dynamic behaviour; that is, flutter instabilities are not an issue for curved wings. To obtain more robust results for the dynamic case a new campaign of numerical analyses was carried out.

We applied the FSI technique by means of ANSYS Workbench $^{\circledR}$ Rel. 15 commercial platform. The dynamic responses of a swept wing and a curved wing were studied and compared. The models of the two wings, as assumed in previous researches, were constructed with similar aerodynamic profiles, aspect ratios, sweep angles at the root section, and structural layouts. The geometry of the curved wing was obtained by shearing the swept wing in the longitudinal direction. Figures 1 and 2(a) show the planform shape of the
TABLE 1: Geometrical data of the two half-wing models.

\begin{tabular}{lcc}
\hline & Swept wing & Curved wing \\
\hline AR (aspect ratio) & 9.5 & 9.5 \\
Angle of sweep at root & $32^{\circ}$ & $32^{\circ}$ \\
Angle of sweep at tip & $32^{\circ}$ & $53^{\circ}$ \\
Half-wing span $(b / 2)$ & $30 \mathrm{~m}$ & $30 \mathrm{~m}$ \\
Reference surface area & $379 \mathrm{~m}^{2}$ & $379 \mathrm{~m}^{2}$ \\
Root chord & $13.18 \mathrm{~m}$ & $13.18 \mathrm{~m}$ \\
Tip chord & $1.7 \mathrm{~m}$ & $1.7 \mathrm{~m}$ \\
Kink section position $\left(b_{K} / 2\right)$ & $9.3 \mathrm{~m}$ & $9.3 \mathrm{~m}$ \\
Kink chord & $7.373 \mathrm{~m}$ & $7.373 \mathrm{~m}$ \\
Dihedral angle & $5^{\circ}$ & $5^{\circ}$ \\
\hline
\end{tabular}

two wings analysed. Table 1 summarizes the geometrical data of the models. Equation (1) describes the in plant shape of the leading edge of the curved wing (starting from a point at the leading edge position of the kink chord).

In (1) $t$ is a nondimensional parameter $(0 \leq t \leq 1), b$ is the span of the wing, and $b_{K}$ is the span at the kink chord (both expressed in meters; see Table 1 ).

The $s(t)$ coordinate (unit $=\mathrm{m}$ ), which defines the geometry of the leading edge, is measured in the longitudinal direction (aerodynamic chord direction): $s(0)=0$ corresponds to the leading edge of the kink section, while $s(1)=19.359 \mathrm{~m}$ corresponds to the leading edge of the tip section, as shown in Figure 2(b):

$$
\begin{aligned}
s(t)= & 6.2487 \times 10^{-1} \cdot t \cdot\left(\frac{b-b_{K}}{2}\right)+1.1054 \times 10^{-2} \\
& \cdot t^{2} \cdot\left(\frac{b-b_{K}}{2}\right)^{2}+1.9022 \times 10^{-4} \cdot t^{3} \\
& \cdot\left(\frac{b-b_{K}}{2}\right)^{3} .
\end{aligned}
$$

For both wings an engine nacelle was modelled at the kink chord position. In the structural analyses for the two half wings, the root section was assumed clamped.

The combined fluid dynamic and structural analyses were carried out by taking into account the gravity effects and setting the proper geometrical angle of attack in order to get the same lift coefficient for both wings. Following previous experiences [18-20] the dynamic response analyses were also 


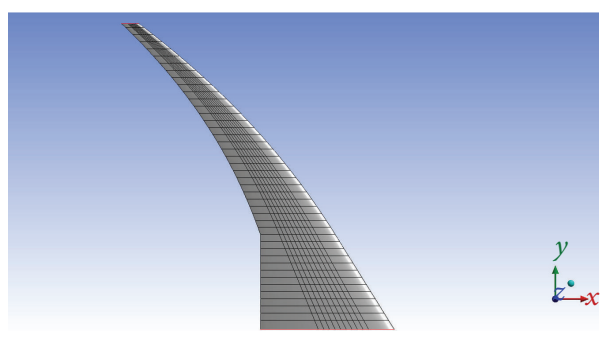

(a)

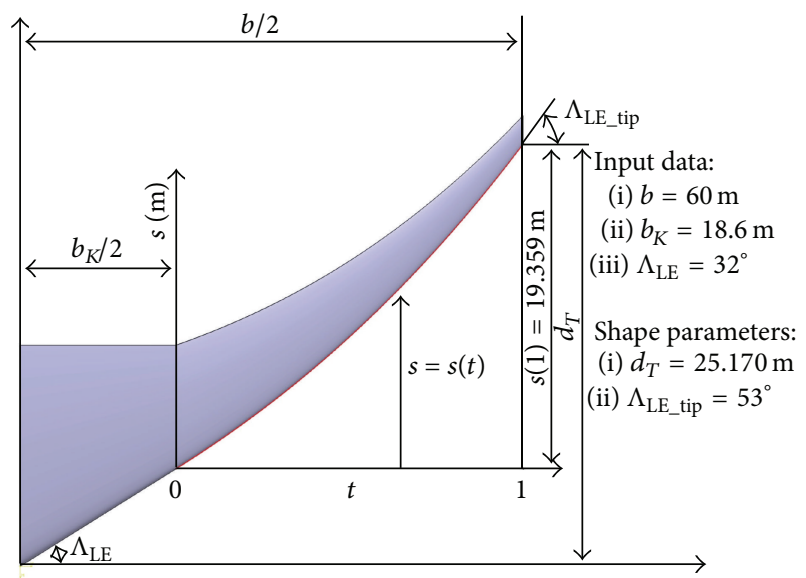

(b)

Figure 2: (a) Curved wing model. (b) Definition of leading edge geometry of the curved wing model.

executed by imposing different values for the asymptotic Mach number and the altitude of flight.

The elasticity and damping effects obviously influence the final response of the wings providing, for example, suitable displacement histories for fixed control points. The nodes of the finite element models positioned at the leading edge and at the trailing edge of the tip section of the two wings were assumed as control points. Thus, for each flight condition, the overall damping coefficient (which involves both structural and aerodynamic effects) was extracted by processing the displacement time history of the two wings.

The two wing models were constructed by adopting similar structural layouts (aluminium alloy material), similar thickness distribution for skins, and similar geometry for spars and stringers. The structural mass of the models is the same, also including the effect of fuel mass distributed along the span.

During a preliminary numerical campaign, carried out at sea level, neither of the wing models suffered from instability. In fact, the overall damping was always negative in the range values of the Mach number examined. This result depended on the scheme used to define the structural models. In fact in the present models, not only does the wing box affect the structural response but also the front and rear portions of the wing cross sections outside the wing box do. Thus in particular the estimated torsional natural frequencies of the wings were found to be unrealistic: the first torsional frequency was too high with respect to the first bending frequency. To overcome this problem, fictitious rotational inertia was added to the last three ribs at the tip region of the wings, thus keeping the total mass of the two wings unchanged.

This adaptation of the models provided the desired results: the reduction of the torsional frequency, the interaction of first bending and torsional modes, and the onset of dynamic instability for both wings.

Comparing the two wings, with similar aerodynamic profiles and structural layouts, reveals that for a curved geometry the dynamic instability conditions are reached with higher flight velocity values. This occurs at sea level for low subsonic flight conditions and at cruise altitude for high subsonic flight conditions (transonic flight).

The results obtained highlight the need for further research because, as demonstrated in previous studies $[16,18-$ 20 ] the curved wing configuration itself leads to a reduction in the drag from the aerodynamic point of view (which means saving fuel). In addition, with a fixed flutter boundary, the curved configuration enables lighter structures to be used (which means further fuel savings). Alternatively, with an enlarged flutter boundary, the curved configuration enables faster machines to be designed without changing the aerodynamic efficiency.

\section{Fluid Dynamic Models of the Wings}

To carry out the fluid dynamic analyses the FLUENT ${ }^{\circledR}$ code was adopted. For the two wings structured meshes were constructed, maintaining a similar topology for both models. Thus numerical effects and/or numerical errors can be assumed as similar for the two models (this approach has also been adopted in previous works).

Firstly, a blocking procedure was used to define the control volumes around the wings models (e.g., Figures 3(a) and 3(b) show partial views of the block layout around the curved wing model). The volumes near the wings were constructed allowing for a good level of approximation in order to model the boundary layer. However, a lack of computational resources prevented a more detailed description of local phenomena (transition and/or boundary layer separation).

The section profile geometry that we adopted is similar to that used in previous research campaigns [16, 18-20], that is, the supercritical airfoil SC(2)-0410 [21].

The whole aerodynamic field analysed has the following dimensions: height $131 \mathrm{~m}$, width $90 \mathrm{~m}$, and length $278 \mathrm{~m}$. To minimize the time needed for the analyses a whole grid of only 389766 hexahedral cells and 400544 nodes was used. Figure 4 shows the surface grid of the curved wing model.

The boundary conditions fixed for the lateral surfaces of the overall mesh volume are summarized in Table 2. In 


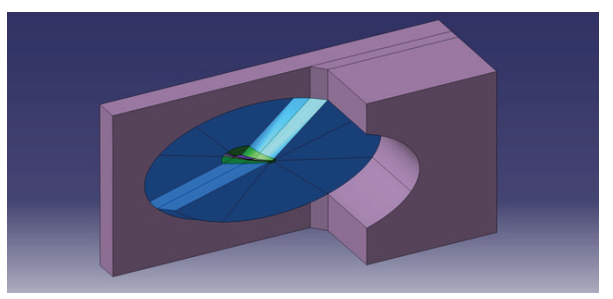

(a)

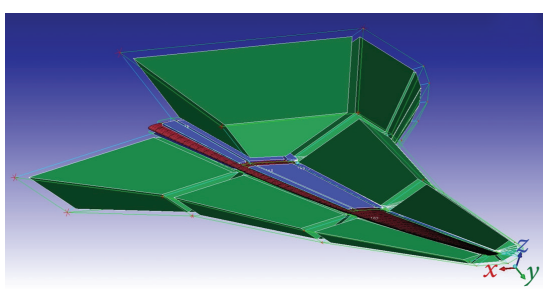

(b)

Figure 3: (a) Block layout around the curved wing model (partial view). (b) Block layout near the curved wing model (partial view).

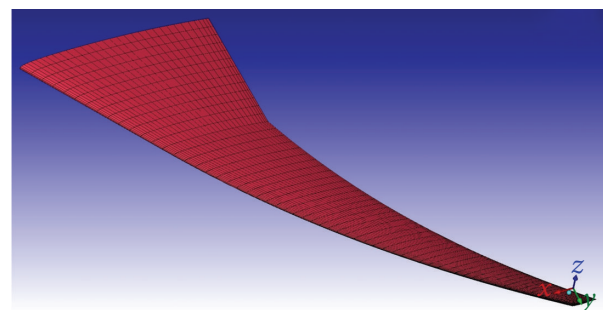

FIGURE 4: Surface grid of the curved wing model.

TABLE 2: CFD boundary conditions.

\begin{tabular}{lcc}
\hline & Swept wing model & Curved wing model \\
\hline Altitudes analysed & $0 \mathrm{~m}-10000 \mathrm{~m}$ & $0 \mathrm{~m}-10000 \mathrm{~m}$ \\
Pressure far field & Front side up down & Front side up down \\
Pressure outlet & Rear & Rear \\
Symmetry & Center-line plane & Center-line plane \\
Wall/no slip & Wing surface & Wing surface \\
\hline
\end{tabular}

order to take into account the viscosity effects, a viscous and turbulent flow was assumed during the CFD analyses. A standard $K-\varepsilon$ model was used to describe the turbulence and an implicit unsteady analysis technique was adopted. The objective of our CFD analysis was to compare the dynamic behaviour of two different lifting systems and to draw damping-Mach curves for the two configurations. Starting from rigid CFD results, the dynamic analysis of the two wing models was based on similar values of the lifting coefficient equal to 0.36 for a Mach equal to 0.85 in hypothetical cruise flight conditions $h=10000 \mathrm{~m}$.

\section{Structural Models of the Wings}

The models of the swept and curved wings were constructed by assigning the properties to the structural components (skin, stringers, ribs, and spars) in ANSYS R15.0. All the components of both structural wing models have the same dimensions. The structures were modelled with a metallic material (aluminium alloy). A three-spar configuration was assumed for the wing box layout. Upper and lower skin, ribs, and spar webs were modelled with shell elements, whereas the stringers and spar flanges were modelled with beam elements. Both the models consist of 8436 nodes and 4157 elements.
Figures 5(a) and 5(b) show the finite element model of the curved wing.

The engine nacelle was modelled with beams with a very high stiffness and three-point masses describe the inertial effects of the engine. The structural mass and the fuel mass distributed along the wing are the same for both wings (swept and curved).

Fictitious inertia values were added on the tip region of the two wings to facilitate the dynamic instability and to overcome the effects of the boundary conditions at the root section of the wing models (the root section was assumed to be clamped for the wings). Two distinct moment inertia distributions were analysed: in the first case (Case 1 in Table 3), very low values for the instability Mach number were obtained. To describe a more realistic situation (in other words higher values for the flutter velocities), a second fictitious inertia distribution (Case 2 in Table 3) was assumed with a reduction of about $50 \%$ in the swept wing and $30 \%$ in the curved wing. Main characteristics of both finite element models are summarized in Table 3.

The structural damping factor $\zeta$, as a function of the natural circular frequency $\omega_{n}$, was introduced during the coupled CFD and transient response analyses according to the Rayleigh method (2).

The modal analyses enabled the values of $\alpha$ and $\beta$ of (2) to be defined assuming a structural damping factor equal to 0.04 for two fixed natural frequencies; that is $f_{1}=1 \mathrm{~Hz}$ and $f_{2}$ $=6 \mathrm{~Hz}$. Consider

$$
\begin{aligned}
\zeta\left(\omega_{n}\right)=\frac{\alpha}{2 \cdot \omega_{n}}+\frac{\beta}{2} & \omega_{n} ; \\
\alpha & =\frac{2 \cdot \omega_{1} \cdot \omega_{2}}{\omega_{1}+\omega_{2}} \cdot \bar{\zeta} ; \beta=\frac{2}{\omega_{1}+\omega_{2}} \cdot \bar{\zeta}
\end{aligned}
$$


TABLE 3: Structural analyses data.

\begin{tabular}{lcc}
\hline & Swept wing & Curved wing \\
\hline Material & Aluminium alloy & Aluminium alloy \\
Skin thickness & $7 \mathrm{~mm}$ to $2.5 \mathrm{~mm}$ & $7 \mathrm{~mm}$ to $2.5 \mathrm{~mm}$ \\
Rib thickness & $7 \mathrm{~mm}$ to $1 \mathrm{~mm}$ & $7 \mathrm{~mm}$ to $1 \mathrm{~mm}$ \\
Front spar thickness & $12 \mathrm{~mm}$ to $5 \mathrm{~mm}$ & $12 \mathrm{~mm}$ to $5 \mathrm{~mm}$ \\
Central spar thickness & $12 \mathrm{~mm}$ to $8 \mathrm{~mm}$ & $12 \mathrm{~mm}$ to $8 \mathrm{~mm}$ \\
Rear spar thickness & $12 \mathrm{~mm}$ to $7.5 \mathrm{~mm}$ & $12 \mathrm{~mm}$ to $7.5 \mathrm{~mm}$ \\
Total structural mass & $15372.2 \mathrm{~kg}$ & $15372.2 \mathrm{~kg}$ \\
Total fuel mass & $20000 \mathrm{~kg}$ & $20000 \mathrm{~kg}$ \\
Engine masses & $45394 \mathrm{~kg}$ & $4000 \mathrm{~kg}$ front, $4000 \mathrm{~kg}$ centre, and $2000 \mathrm{~kg}$ rear \\
Total model mass & $1300^{\mathrm{a}}, 1000^{\mathrm{a}}, 1000^{\mathrm{a}}$ & $45394 \mathrm{~kg}$ \\
Fictitious inertia (Case 1) & $750^{\mathrm{a}}, 500^{\mathrm{a}}, 500^{\mathrm{a}}$ & $1300^{\mathrm{a}}, 1000^{\mathrm{a}}, 1000^{\mathrm{a}}$ \\
Fictitious inertia (Case 2) & $1050^{\mathrm{a}}, 700^{\mathrm{a}}, 700^{\mathrm{a}}$
\end{tabular}

${ }^{\mathrm{a}}$ Moment of inertia applied on ribs in the tip region ( $y$ direction): units $=\mathrm{kg} \mathrm{m}^{2}$.

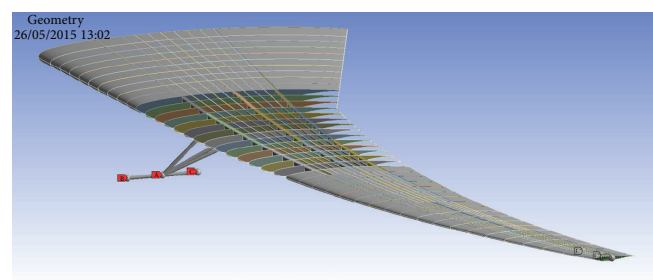

(a)

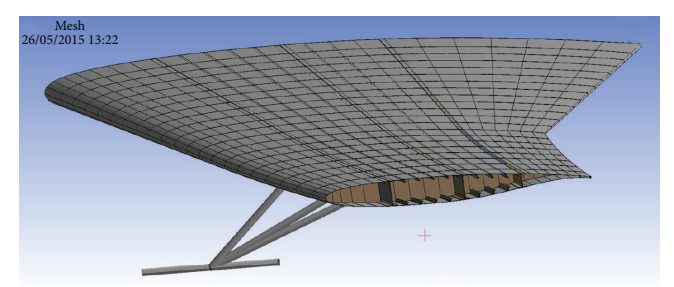

(b)

Figure 5: (a) The finite element model of the curved wing (upper and lower skins partially removed). (b) The finite element model of the curved wing (wing structure layout).

TABLE 4: Results of modal analysis: Case 0 (no fictitious moments of inertia were added to finite element models).

\begin{tabular}{lcc}
\hline & Swept wing & Curved wing \\
\hline First bending mode: Case 0 & $1.058 \mathrm{~Hz}$ & $0.916 \mathrm{~Hz}$ \\
& Mode N. 1 & Mode N. 1 \\
First torsion mode: Case 0 & $12.633 \mathrm{~Hz}$ & $12.733 \mathrm{~Hz}$ \\
& Mode N. 8 & Mode N. 9 \\
\hline
\end{tabular}

with $\bar{\zeta}=0.04$ for $\omega_{1}=2 \cdot \pi \cdot f_{1}$ and $\omega_{2}=2 \cdot \pi \cdot f_{2} ; \alpha=0.431$ and $\beta=1.82 \times 10^{-3}$.

3.1. Results of Modal Analysis of the Wings. Before activating the fluid structure interaction, modal analyses of the wing models were carried out to study the distribution of the natural frequencies and the shape of the associated normal modes. For the two models, Table 4 shows the bending and the torsional natural frequencies, whose coupling usually leads to dynamic aeroelastic instability for slender wings, without the effect of fictitious inertia positioned at the tip (Case $0)$.

Table 4 highlights that the first torsion mode has a frequency that is too high compared to the bending mode frequency and to typical engineering applications of similar wing structures. The classical flutter of a wing involves the interaction (inertial and aerodynamic) of bending and torsion modes. However if the frequencies of these modes are too far apart, their physical interactions are probably nil. Our results of the modal analyses are strongly affected by the discretization method of the wing structure. Unfortunately, because of geometrical matching requirements and in order to allow for a suitable data exchange between the mechanical and the fluid dynamic meshes, the portions of the wing models outside the wing box (see Figures 5(a) and 5(b)) deeply influence the mechanical response of the structure. As a consequence, for both wings, the frequency of the first torsion mode is too high with respect to the frequency of the first bending mode, as shown in Table 4. This situation does not correspond to the realistic dynamic behaviour of a transport aircraft wing; in fact, for these wing models, the preliminary FSI simulations did not reveal flutter. In order to reduce the first torsional frequency down to a more realistic value, we decided to add fictitious rotary inertia at the tip of the two wings without changing their total mass. These inertia values were added around the $y$-axis of the models (as shown in Figures 1 and 2(a)) without affecting the first bending frequencies (Case 1 in Table 3). This method considerably reduced the first torsional mode frequencies, as shown in Table 5; however these wing models reached the flutter conditions for lower Mach numbers than expected. In fact, some of the literature results related to large transport aircrafts [22] had given indications on typical values of Mach numbers along the flutter boundary. Thus we decided to 
TABLE 5: Results of modal analysis: Case 1 and Case 2.

\begin{tabular}{lcc}
\hline & Swept wing & Curved wing \\
\hline $\begin{array}{l}\text { First bending mode (N. 1) } \\
\text { (Case 1; see Table 3) }\end{array}$ & $1.057 \mathrm{~Hz}$ & $0.913 \mathrm{~Hz}$ \\
$\begin{array}{l}\text { First torsion mode (N. 4) } \\
\text { (Case 1; see Table 3) }\end{array}$ & $3.402 \mathrm{~Hz}$ & $3.089 \mathrm{~Hz}$ \\
$\begin{array}{l}\text { First bending mode (N. 1) } \\
\text { (Case 2; see Table 3) }\end{array}$ & $1.057 \mathrm{~Hz}$ & $0.914 \mathrm{~Hz}$ \\
$\begin{array}{l}\text { First torsion mode (N. 5) } \\
\text { (Case 2; see Table 3) }\end{array}$ & $4.417 \mathrm{~Hz}$ & $3.729 \mathrm{~Hz}$ \\
\hline
\end{tabular}

reduce the fictitious rotary inertia in order to increase the frequency of the first torsion mode of both wings. On the other hand, as will be discussed in the next section, in Case 1 the swept wing showed a more critical behaviour with respect to the curved wing both at sea level and at cruise altitude. Thus a stronger reduction of the inertia was applied to the swept wing finite element model (Case 2 in Table 3). It was thus possible to compare the dynamic aeroelastic behaviour of the two wings with different planforms under fully transonic flow conditions. It was also possible to highlight the better performance of the curved wing also under more critical mechanical conditions: a smaller gap between the first bending and first torsion modes frequencies (as summarized in Table 5).

Finally, as expected the first bending frequencies remain unchanged in the three cases examined (Case 0: Table 4; Case 1 and Case 2: Table 5).

\section{Results of the Fluid Structure Interaction Analyses}

On the basis of the preliminary results of the modal analyses, the final fluid structure interaction analyses were carried out for two altitude values: sea level $(0 \mathrm{~m})$ and cruise condition (10000 m).

The time step for the fluid dynamic analyses was fixed at $0.01 \mathrm{~s}$. The time step for the structural analyses was fixed at $0.0025 \mathrm{~s}$. To minimize errors during the data exchange between the structural and the fluid dynamic modules five coupling iterations per time step were set. To obtain the overall damping factor $\zeta$, from the time histories of the vertical displacement $V(t)$ of a node positioned at the leading edge of the wing tip sections, two pairs of relative maxima and minima were extracted as explained below.

Assuming that, close to the flutter condition, a damped harmonic oscillation occurs, $V(t)$ can be expressed as

$$
\begin{array}{r}
V(t)=\widetilde{V} \cdot e^{-\zeta \cdot \omega_{n} \cdot t} \cdot \cos \left(\omega_{d} \cdot t+\phi\right) \\
\text { with } \omega_{d}=\sqrt{1-\zeta^{2}} \cdot \omega_{n}
\end{array}
$$

where $t$ is the time variable, $\phi$ is the phase, and $\omega_{n}$ is the undamped natural circular frequency. The damping factor $\zeta$ is estimated according to the following standard relationships:

$$
\begin{aligned}
& \delta=\frac{1}{j} \cdot \ln \left(\frac{V_{1}^{\mathrm{MAX}}-V_{1}^{\mathrm{MIN}}}{V_{1+j}^{\mathrm{MAX}}-V_{1+j}^{\mathrm{MIN}}}\right) ; \\
& \zeta=\frac{\delta}{\sqrt{(2 \cdot \pi)^{2}+\delta^{2}}},
\end{aligned}
$$

where $\delta$ is the logarithmic decrement, $j$ is the number of cycles between the first couple and the last couple of data extracted from the time history, and $V_{1}^{\mathrm{MAX}}$ and $V_{1}^{\mathrm{MIN}}$ are the maximum and minimum values of the first useful cycle of the generic time history data, while $V_{1+j}^{\mathrm{MAX}}$ and $V_{1+j}^{\mathrm{MIN}}$ are the corresponding values after $j$ cycles. To estimate the damping factor, (4) was assumed to be also valid far from the pure flutter condition where the oscillation is dominated by a single frequency: the flutter frequency. When the time history seemed more complex than a single component response, the maxima, minima, and the appropriate value for $j$ were selected by taking into account the periodicity of the time history itself. Figure 6 shows the described procedure considering the time history for Case 1 relevant to the curved wing at the sea level.

From a practical point of view a dynamic instability condition exists if the parameter $\zeta$ reaches a negative value corresponding to a monotonic growth of the amplitude of the wing structure oscillations. Obviously in the present case there is an interaction between the aerodynamic loads and the (dynamic) deformed shape of the structure. The aerodynamic loads generally introduce dissipative effects, which increase the overall damping of the system. However for each altitude of flight, there is a limit value for the airflow velocity (or Mach) corresponding to a limit for the dynamic stability of the system. As it is well known a pure harmonic motion exists for $\zeta=0$, and from (3) $\omega_{d}=\omega_{n}$ represents the flutter natural circular frequency, and the corresponding velocity (or Mach) is said to be the flutter speed (or Mach).

For both wings, Case 0 was found to be stable for all Mach numbers (at sea level and at the cruise altitude). This depends on the very high values of the torsion natural frequency of both wings (Table 4).

For Case 1 (see Tables 3 and 5), the sea level flight condition was studied first. The highest value of the moment of inertia was applied on the rib positioned exactly at the wing tip. Figures 7 and 8 show the vertical displacement histories of the control node positioned at the leading edge of the tip section for the swept wing and for the curved wing, respectively.

At the sea level $(h=0 \mathrm{~m})$ both wings are unstable, but for the swept wing, the instability condition corresponds to a lower Mach number ranging from 0.4 to 0.45 (see also Figure 15).

The time histories for the cruise flight conditions $(h=$ $10000 \mathrm{~m}$ ) are represented in Figures 9 and 10 for the swept wing and for the curved wing, respectively. Also in this case the swept wing reaches the instability condition for lower Mach number (between 0.7 and 0.8 as shown in Figure 15). 


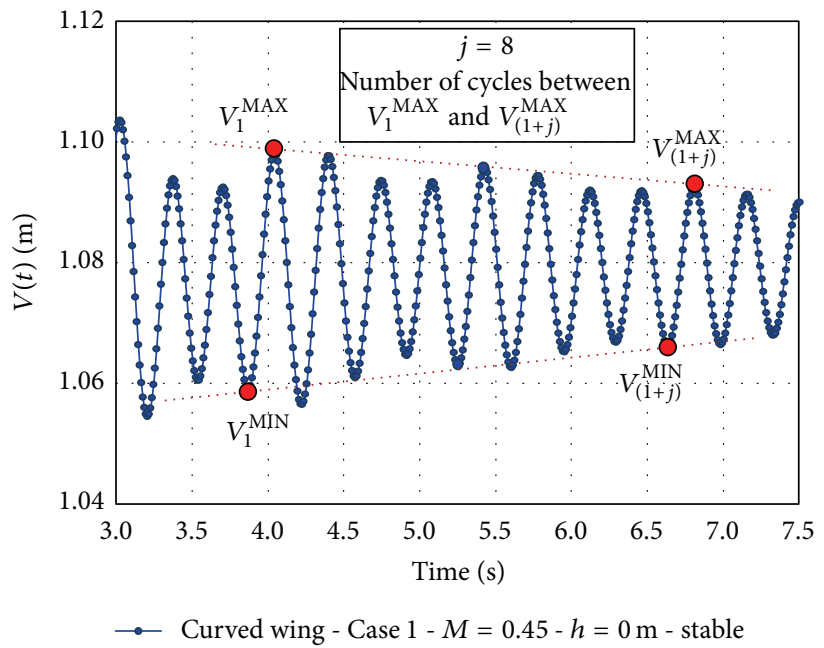

FIgURE 6: Time history of LE vertical displacement of the curved wing (Case 1: sea level, see Figure 8).

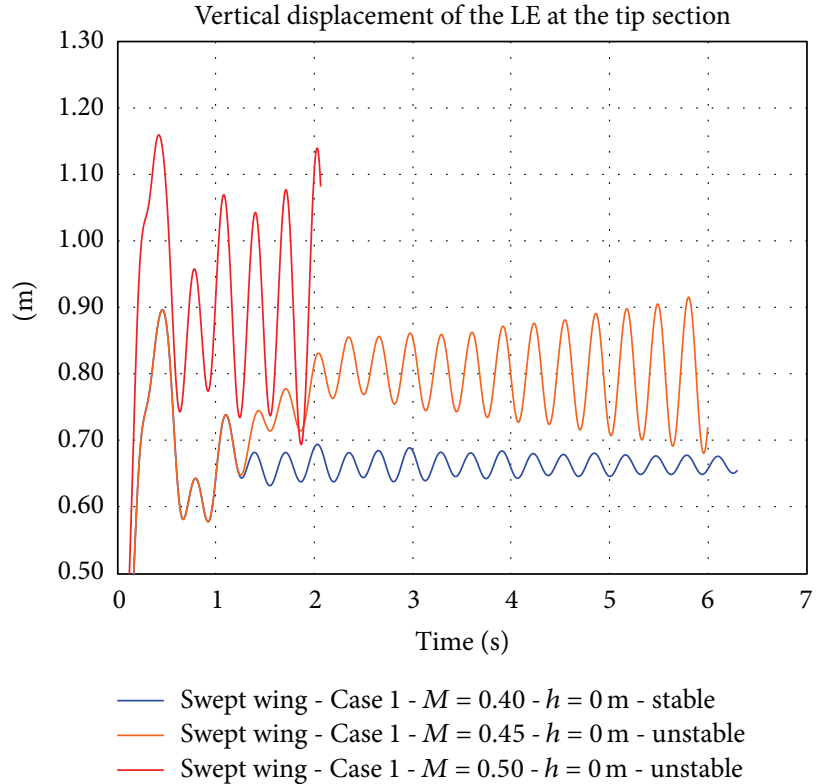

FIGURE 7: Results of the FSI analyses of the swept wing (Case 1, sea level).

On the basis of this first set of analyses, related to the distribution of fictitious moments of inertia corresponding to Case 1 , both the wings clearly reach the instability conditions at sea level and at the cruise flight altitude. However the flutter conditions observed happen for subsonic airflows; in other words around the two wings, the flow is subsonic at each point of the aerodynamic field. This is an interesting result, because, for fully subsonic flight conditions, with all other design parameters fixed, the planform shape of the curved wing leads to an important increase in wing flutter speed. In Case 1 the flutter instabilities involve the interaction of the first bending mode with the first torsion mode of the two wings.

To confirm this last result also for a transonic flight condition, typical of modern transport aircrafts of a medium and/or long operative range, a second distribution of fictitious moments of inertia was adopted. In Case 2 (see Tables 3 and 5 ) the moments of inertia were halved for the swept wing, while as a precaution, for the curved wing a weaker reduction was assumed. As expected, the new distributions of moments of inertia provide different natural frequency values for first torsion modes (Table 5).

In this second case, for both wings, the instability condition corresponds to higher Mach numbers and the supersonic zones around the two wings occupy large zones of the aerodynamic field near the surfaces of wings (see Figures 11(a), 11(b), 12(a) and 12(b)).

The Reynolds numbers related to the represented supersonic zones are $\operatorname{Re}=5.835 \times 10^{7}$ for $M=0.875$ and $\operatorname{Re}=6.001$ $\times 10^{7}$ for $M=0.90$. 


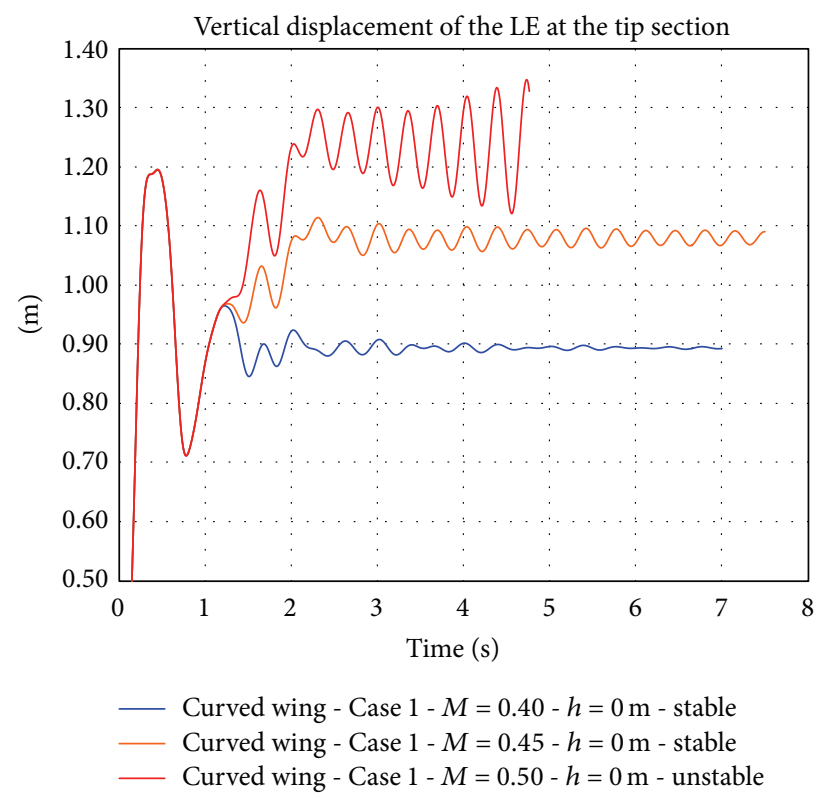

FIGURE 8: Results of the FSI analyses of the curved wing (Case 1, sea level).

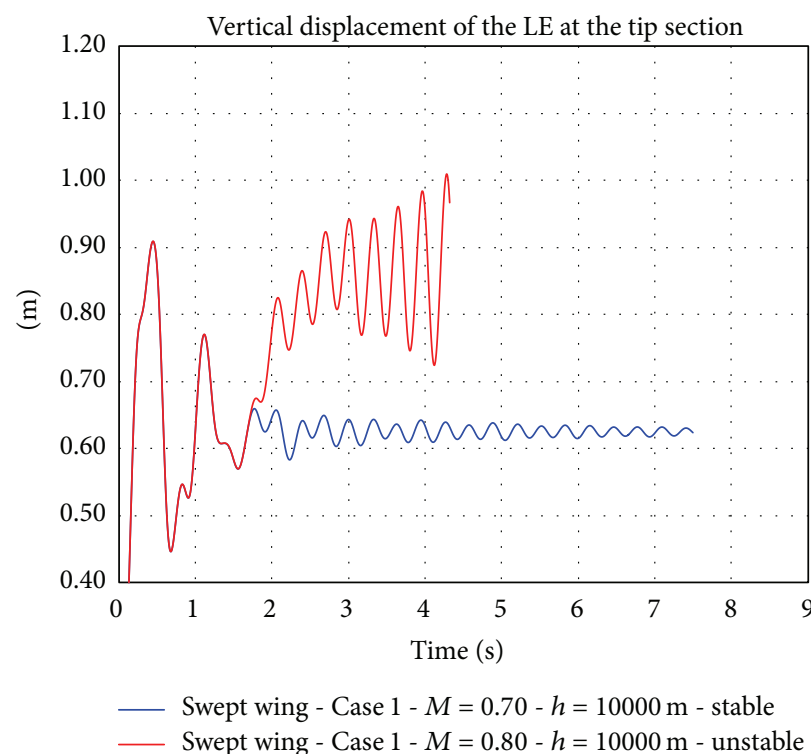

FIgURE 9: Results of the FSI analyses of the swept wing (Case 1, cruise altitude).

The aerodynamic fields are now fully transonic and shock waves develop on both the wings during the dynamic oscillations. As it is well known, this physical phenomenon represents a source of a strong nonlinearity from a mathematical point of view.

Nevertheless, in the present work, the well-structured aerodynamic grids were able to describe the complex aeroelastic behaviour of the two wing models very well, even though the adopted level of grid refinement was not very high due to the available computational resources. In a previous work it was also demonstrated that adopting well-structured grids (similar to fluid dynamic grids used in the present work), also with a low level of refinement, the numerical distributions of the pressure coefficient agree very well with the available experimental data [17]. For this reason, the present results describe in a reliable way the pressure field and the physical phenomena that develop on the two wings.

During the oscillating motion of the wings (flexural and torsional) the shock waves move in a chordwise direction due to the continuous change in the angle of attack along the wing span. The motion of the shock wave increases the complexity of the aeroelastic phenomena and the computational difficulties.

For Case 2, Figures 13 and 14 show the displacement time histories at the control node of the two wings calculated only for the cruise flight condition $(h=10000 \mathrm{~m})$. It is well 


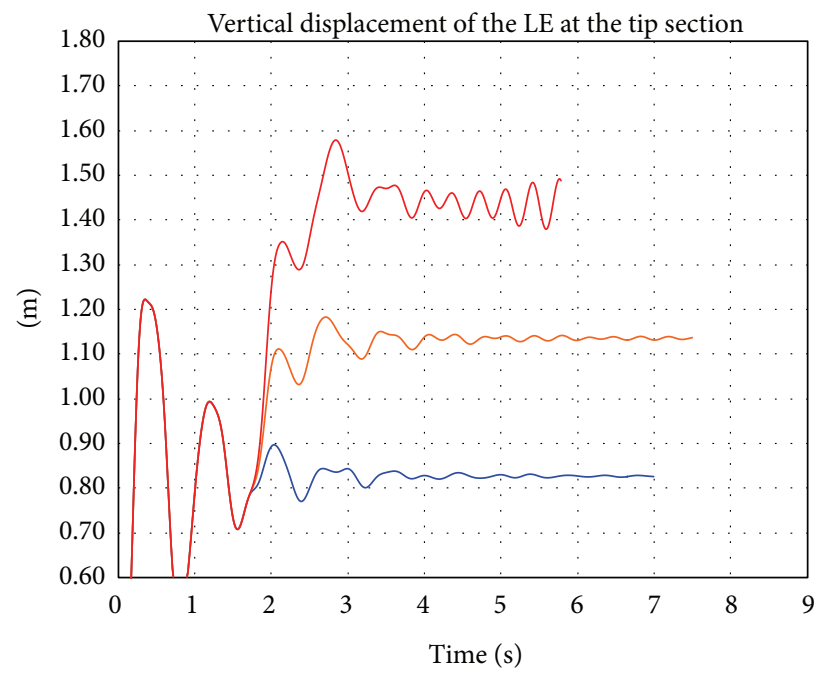

Curved wing - Case $1-M=0.70-h=10000 \mathrm{~m}$ - stable
Curved wing - Case $1-M=0.80-h=10000 \mathrm{~m}$ - stable
Curved wing - Case $1-M=0.90-h=10000 \mathrm{~m}$ - unstable

FIGURE 10: Results of the FSI analyses of the curved wing (Case 1, cruise altitude).

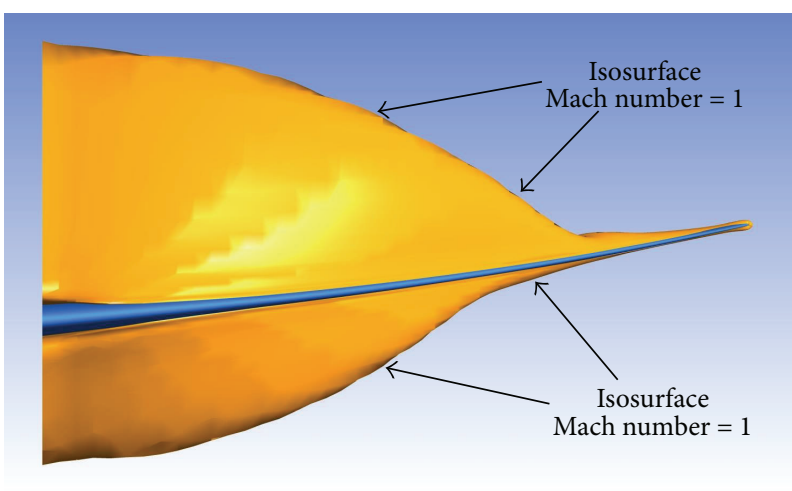

(a)

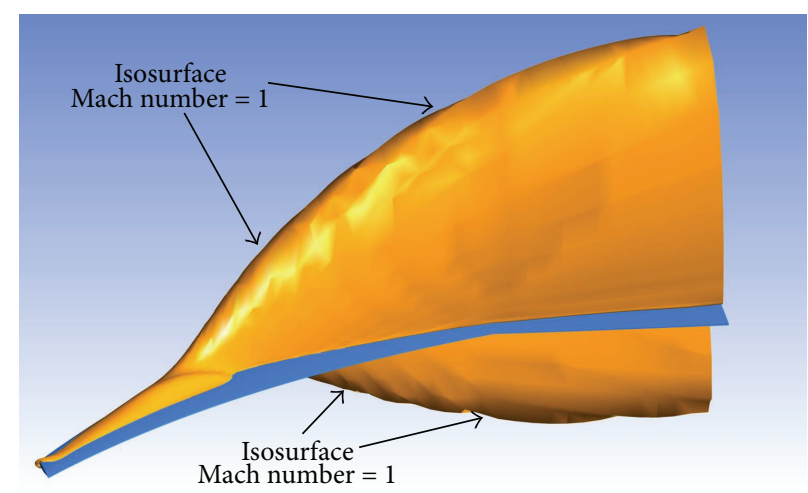

(b)

FIGURE 11: (a) Front view of the supersonic zone around the curved wing (Case 2, Mach $=0.90$, time $=6.5 \mathrm{~s}$ ). (b) Rear view of the supersonic zone around the curved wing (Case $2, \mathrm{Mach}=0.90$, time $=6.5 \mathrm{~s}$ ).

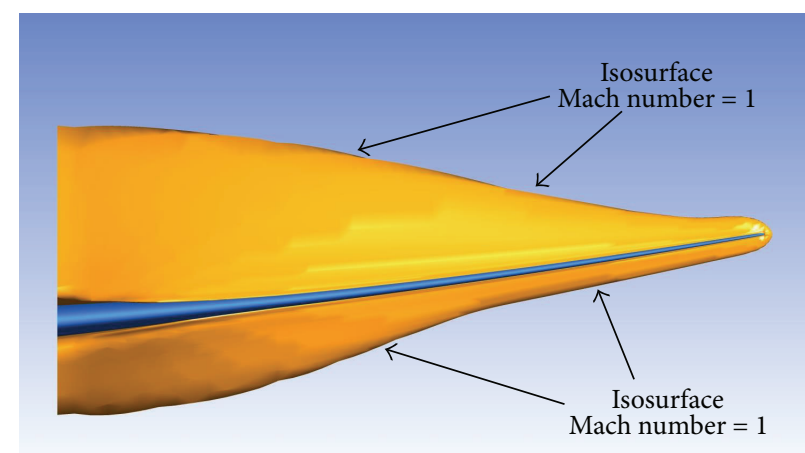

(a)

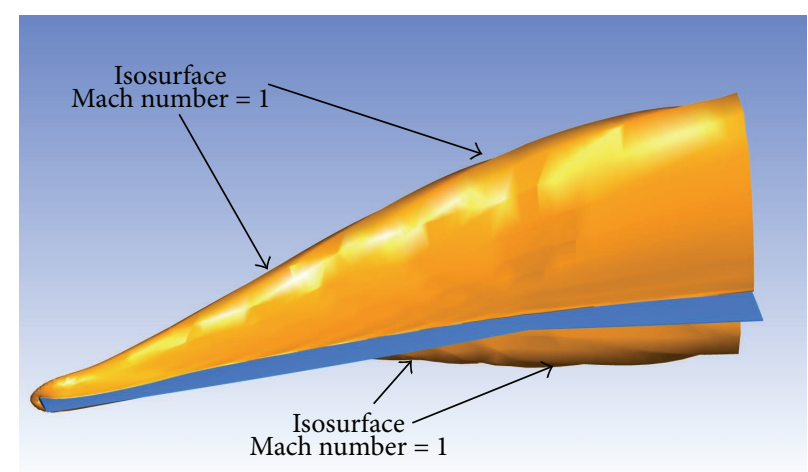

(b)

Figure 12: (a) Front view of the supersonic zone around the swept wing (Case 2, Mach $=0.875$, time $=7 \mathrm{~s}$ ). (b) Rear view of the supersonic zone around the swept wing (Case $2, \mathrm{Mach}=0.875$, time $=7 \mathrm{~s}$ ). 


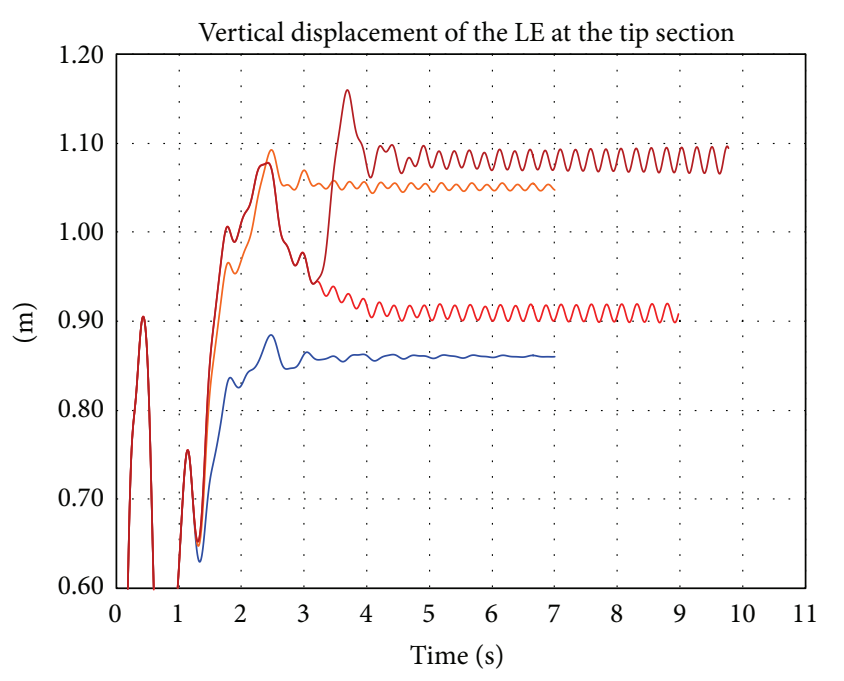

Swept wing - Case $2-M=0.80-\alpha=0.76 \mathrm{deg}-h=10000 \mathrm{~m}-$ stable
Swept wing - Case $2-M=0.875-\alpha=0.76 \mathrm{deg}-h=10000 \mathrm{~m}-$ stable
Swept wing - Case $2-M=0.90-\alpha=0.76 \mathrm{deg}-h=10000 \mathrm{~m}$ - unstable
Swept wing - Case $2-M=0.90-\alpha=0.977 \mathrm{deg}-h=10000 \mathrm{~m}$ - unstable

FIGURE 13: Results of the FSI analyses of the swept wing model (Case 2, cruise altitude).

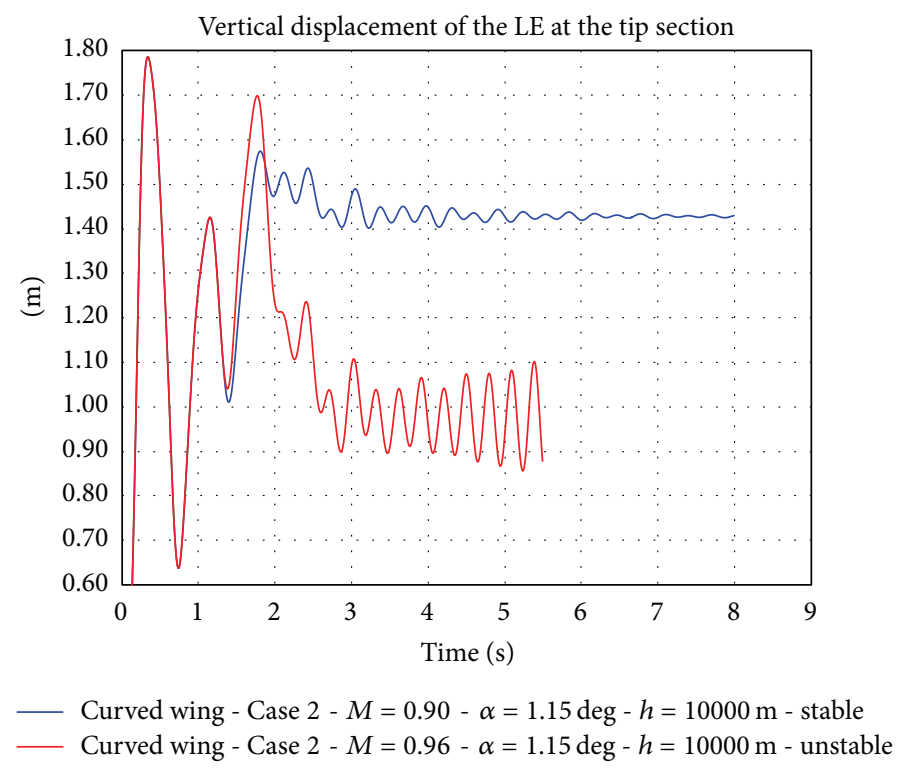

FIGURE 14: Results of the FSI analyses of the curved wing model (Case 2, cruise altitude).

known (see [11] or [23]) that approaching the transonic regime, for a fixed value of the angle of attack, because of the strong interaction between the shock wave and the boundary layer, the lift of rigid profiles tend to be reduced when the Mach number increases. This, in addition to the threedimensional effects generated by the sweep angle, reduces the lift coefficient of the wing (if the angle of attack at the root section is fixed, as in the present analyses). In addition, taking the elasticity effects into account, a reduction in the displacement at the wing tip can be observed.

This phenomenon related to the swept wing is clearly evident in Figure 13. The asymptotic mean value of the vertical displacement of the control node reaches a maximum value for Mach $=0.875$ and subsequently falls down for Mach $=0.90$ for a fixed geometric angle of attack equal to $0.76 \mathrm{deg}$. To maintain a similar value of the rigid lift coefficient for Mach $=0.90$, the geometric angle of attack of the swept wing model was increased to $0.977 \mathrm{deg}$, thereby obtaining the upper curve in the graph of Figure 13.

Likewise, for the curved wing, as shown in Figure 14, the asymptotic mean value of vertical displacement falls down for Mach $=0.96$.

As the present analyses are aeroelastic, both conditions considered, for which the lift and the deformed shape fall 


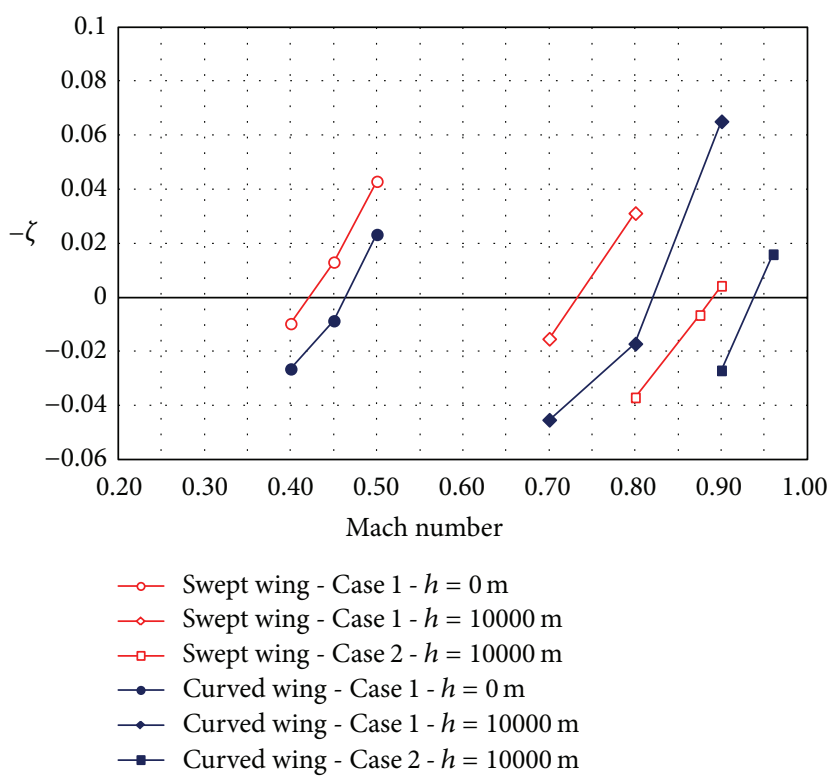

FIGURE 15: Damping ratio versus Mach (the damping data are represented with the opposite sign).

down, represent unstable motions of the wings for Case 2. For the swept wing the unstable small amplitude bending oscillations probably depend directly on the development of buffet phenomenon: a dynamic interaction between the shock wave and the separation of the boundary layer which produces an unsteady variation in the pressure distribution along the chord of the wing. The buffet phenomenon is well known in literature and is studied, as an example, in [24-26] and in the experimental research discussed in [27]. Even if all of these cited works refer to three-dimensional configurations, these studies on transonic flow instabilities concern rigid models: in other words the elasticity effects of the wing box structure are not considered assuming that the buffet phenomenon does not depend on elastic deformations of the lifting surfaces. Thus, in the cited references, the instability conditions of the transonic flow field depend only on the interaction between shock waves and boundary layer separation. To the best of our knowledge, in literature are available some studies that include the elasticity effect for analyzing flutter-buffet interaction but only for twodimensional configurations (see as an example [28]).

As said above, the instability condition of the swept wing model examined in the present work seems to be related to a flutter-buffet interaction. In Figure 13 it can be seen that the displacement amplitude of the two unstable histories increases slowly: this fact is directly related to periodic oscillations of shock waves, on both upper and lower skin, near the tip zone of the swept wing model. On the other hand for the curved wing, the unstable oscillations are typical of a bending-torsion flutter instability condition. This fact can be confirmed by observing the displacement amplitude of the unstable history in Figure 14: for the curved wing the amplitude of the oscillations increases rapidly, showing the effect of a classical bending-torsion flutter phenomenon.
Figures 13 and 14 highlight that, also in Case 2 (i.e., a fully transonic regime), the curved planform provides increases in flutter speed. For a typical cruise altitude, the swept wing reaches the instability for a Mach number in the range of $0.8-$ 0.9 , while the curved wing reaches the instability for a Mach number in the range of $0.9-0.96$. In the transonic regime this depends on the different level of energy associated with the development of the shock waves. For a curved planform, the shock waves are weaker, especially toward the tip of the wing (compare Figures 11(a) and 12(a)), and the pressure variations in the chordwise direction are smoother (as discussed in a previous work [16]). Thus by adopting a curved planform wing, the effects of the boundary layer separation can be reduced, and buffeting can thus be delayed.

Figures 15 and 16 compare the analyses. The graphs of the overall damping ratio of the wings were reproduced as a function of the Mach number and True Air Speed, respectively. The damping parameter was estimated using (4) for all the conditions examined.

Case 2 represents a realistic situation by comparing the instability conditions found with the data summarized in [22]. Thus, on the basis of the numerical results obtained in the present research, an increase in the flutter speed greater than $5 \%$ can be estimated for the curved wing compared with a conventional swept wing.

An increase in the flutter speed enables aircrafts to be operated with higher commercial velocity values, thus increasing the productivity of a fleet. On the contrary, the better dynamic response of the curved planform wing enables lighter aircrafts to be designed with a similar flutter boundary of traditional swept wing configurations. In this second case, the saving in weight means a reduction in operative costs. The consequent reduction in fuel consumption also reduces the level of pollution. 

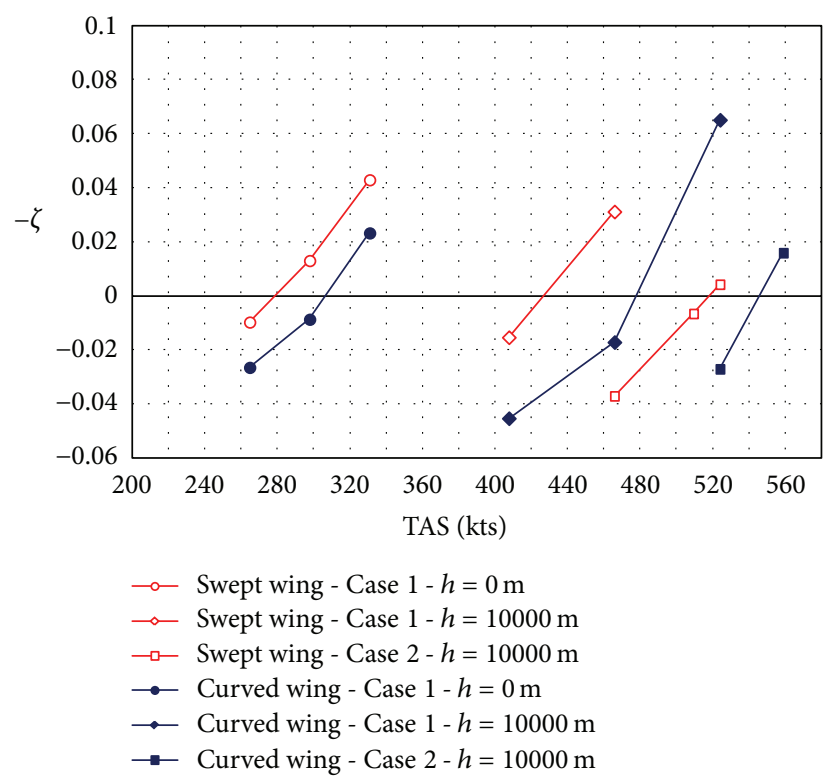

FIGURE 16: Damping ratio versus True Air Speed (the damping data are represented with the opposite sign).

\section{Conclusions}

A campaign of dynamic fluid structure interaction analyses was carried out to investigate the effects of the planform on the stability properties of high aspect ratio wings. As in previous studies, a comparison between a traditional swept wing and a curved planform wing was performed. The numerical models of the wings were constructed maintaining the same aerodynamic profiles, the same span, aspect ratio, value of the sweep angle at root section, structural layout, and total weight. To carry out the analyses commercial software was used (ANSYS Workbench Rel. 15). Using a blocking procedure (Figures 3(a) and 3(b)) structured grids were generated with the same level of refinement for the aerodynamic wing models. Also the structural meshes of the wings were constructed by adopting a similar layout of the elements. Validation of the modelling technique of the structured aerodynamic grids can be found in [17]: in this work, for a forward swept wing model, the computed distributions of the pressure coefficient were compared with experimental pressure measurements executed in a transonic wind tunnel. The comparison between the numerical and experimental data was excellent.

Previous studies have demonstrated that a curved planform wing reduces the drag coefficient. Present aeroelastic analyses show that this type of wing improves the dynamic performances of transport aircrafts. Adopting a fictitious distribution of moments of inertia applied at the tip of the two finite element models, aimed at reducing the first torsion natural frequency of clamped half wings, the fluid structure interaction analyses provided unstable conditions for both wing models. In addition from the numerical time histories of structural displacements, an estimation of the global damping ratio was obtained.
Our results highlight that (a) in the first case analysed both the swept wing and the curved wing reached the flutter condition (at the sea level and cruise altitude) for a subsonic flow field, and the bending-torsion flutter speeds of the curved wing were greater than swept wing; (b) in the second case (with lower values of the fictitious moments of inertia) at the cruise altitude, the flow fields analysed were fully transonic (as shown in Figures 11(a) and 12(a)), and the swept wing reached a flutter-buffet instability condition (in this case the instability phenomenon was related to the interaction between the shock wave movement and the second bending mode of the wing) earlier than the curved wing, for which a classical bending-torsion flutter developed at higher speed.

The results of the present study demonstrate that from a dynamic point of view (i) a curved planform wing shows an excellent performance also in fully subsonic flight conditions and (ii) in the transonic regime, for a curved planform wing, shock phenomena are less critical compared to those occurring on a conventional swept wing.

Figure 16 represents the calculated damping ratio as a function of the True Air Speed. For the second case examined, from this figure it can be estimated as an increment in the critical speed greater than $5 \%$.

These results agree with the preliminary aeroelastic results obtained with the use of the NASTRAN code discussed in [16] and related to a half wing-body configuration. In other words the curved wing shows a good aeroelastic behaviour compared with a conventional swept wing (in [16] the flutter speed of curved wing was found to be higher especially at sea level). The aerodynamic forces in the NASTRAN code are computed according to a linear approach and do not take into account local phenomena due to boundary layer separation effects or to the dynamic interaction of the shock wave with the oscillations of a wing. In this sense, the previous 
results were obtained with some limitation on the unsteady aerodynamic field description. Instead, in the present work, by exploiting the hypotheses concerning the topology of the compared fluid dynamic grids used in nonlinear and unsteady FSI analyses, we have established that, also at cruise altitude and in a fully transonic regime reliably simulated, the flutter speed of a curved wing is higher with respect to a conventional swept wing configuration. Thus these results represent a further step in the technical validation of our proposed novel wing configuration.

\section{Competing Interests}

The authors declare that there are no competing interests regarding the publication of this paper.

\section{References}

[1] G. H. Holdaway and J. A. Mellenthin, "Evaluation of blended wing-body combinations with curved plan forms at mach numbers up to 3.50," NASA 19980227180, 1960.

[2] R. C. Lock, "Design of wing plan forms for transonic speeds," in The Aeronautical Quarterly, Royal Aeronautical Society, vol. 12, pp. 65-93, Royal Aeronautical Society, London, UK, 1961.

[3] M. E. Vaughn Jr. and J. E. Burkhalter, "Pressure loading on curved leading edge wings in supersonic flow," Journal of Aircraft, vol. 23, no. 7, pp. 574-581, 1986.

[4] J. Ashenberg and D. Weihsradius, "Minimum induced drag of wings with curved planform," Journal of Aircraft, vol. 21, no. 1, pp. 89-91, 1984.

[5] C. P. Van Dam, P. M. H. W. Vijgen, and B. J. Holmes, "Experimental investigation on the effect of crescent planform on lift and drag," Journal of Aircraft, vol. 28, no. 11, pp. 713-720, 1991.

[6] G. Heller et al., Wing Tip Extension for a Wing, Pub. No. US2002162917A1, November 2002, http://ep.espacenet.com/.

[7] L. B. Gratzer, “Curved wing tip,” US Patent 20100181432 A1, 2010.

[8] http://www.boeing.com/commercial/787/.

[9] G. Lombardi, "Experimental study on the aerodynamic effects of a forward-sweep angle," Journal of Aircraft, vol. 30, no. 5, pp. 629-635, 1993.

[10] G. Lombardi, M. V. Salvetti, and M. Morelli, "Appraisal of numerical methods in predicting the aerodynamics of forwardswept wings," Journal of Aircraft, vol. 35, no. 4, pp. 561-568, 1998.

[11] A. Kuzmin, "Sensitivity analysis of transonic flow over J-78 wings," International Journal of Aerospace Engineering, vol. 2015, Article ID 579343, 6 pages, 2015.

[12] O. Brodersen and A. Stürmer, "Drag prediction of EngineAirframe interference effects using unstructured Navier-Stokes calculations," in Proceedings of the 19th AIAA Applied Aerodynamics Conference, AIAA 2001-2014, Anaheim, Calif, USA, June 2001.

[13] J. D. Cole and N. D. Malmuth, "Wave drag due to lift for transonic airplanes," Proceedings of the Royal Society of LondonSeries A: Mathematical, Physical and Engineering Sciences, vol. 461, no. 2054, pp. 541-560, 2005.

[14] O. Gur, W. H. Mason, and J. A. Schetz, "Full-configuration drag estimation," Journal of Aircraft, vol. 47, no. 4, pp. 1356-1367, 2010.

[15] M. R. Chiarelli, M. Cagnoni, M. Ciabattari, M. De Biasio, and A. Massai, "Preliminary analysis of a high aspect ratio wing with curved planform," in Proceedings of the Associazione Italiana di
Aeronautica e Astronautica (AIDAA '09), pp. 978-988, Milan, Italy, July 2009.

[16] M. R. Chiarelli, M. Cagnoni, M. Ciabattari, M. De Biasio, and A. Massai, "High aspect ratio wing with curved planform: CFD and FE analyses," in Proceedings of the 27th Congress of the International Council of the Aeronautical Sciences (ICAS '10), pp. 1524-1533, Nice, France, September 2010.

[17] M. R. Chiarelli, G. Lombardi, and A. Nibio, "A straight wing and a forward swept wing compared with a curved planform wing in the transonic regime," in Proceedings of the International Conference of the European Aerospace Societies (CEAS '11), Venice, Italy, 2011.

[18] M. R. Chiarelli, M. Ciabattari, M. Cagnoni, and G. Lombardi, "The effects of the planform shape on drag polar curves of wings: fluid-structure interaction analyses results," in STAR Global Conference 2013, Orlando, Fla, USA, March 2013.

[19] M. R. Chiarelli, M. Ciabattari, M. Cagnoni, and G. Lombardi, "A comparison of the drag polar curves of wings using the fluid-structure interaction analyses," in Proceedings of the Conference of the Italian Association of Aeronautics and Astronautics (AIDAA '13), Naples, Italy, 2013.

[20] M. R. Chiarelli, M. Ciabattari, M. Cagnoni, and G. Lombardi, "Fluid-structure interaction analyses of wings with curved planform: preliminary aeroelastic results," in Proceedings of the Common European Asylum System (CEAS '13), Linköping, Sweden, June 2013.

[21] C. D. Harris, "NASA supercritical airfoils, a matrix of familyrelated airfoils," NASA Technical Paper 2969, Langley Research Center, Hampton, Va, USA, 1990.

[22] K. Koenig, "Pretension and reality of flutter-relevant tests," in Advanced Aeroservoelastic Testing and Data Analysis, AGARDCP-566, North Atlantic Treaty Organization, Brussels, Belgium, 1995.

[23] D. G. Mabey, "Physical phenomena associated with unsteady transonic flows," in Unsteady Transonic AerodynamicsProgress in Astronautics and Aeronautics, vol. 120, American Institute of Aeronautics and Astronautics, Washington, DC, USA, 1989.

[24] J. D. Crouch, A. Garbaruk, D. Magidov, and A. Travin, "Origin of transonic buffet on aerofoils," Journal of Fluid Mechanics, vol. 628, pp. 357-369, 2009.

[25] F. Sartor and S. Timme, "Reynolds-averaged Navier-Stokes simulations of shock buffet on half wing-body configuration," in Proceedings of the 53rd AIAA Aerospace Sciences Meeting, Kissimmee, Fla, USA, 2015.

[26] M. Iovnovich and D. E. Raveh, "Numerical study of shock buffet on three-dimensional wings," AIAA Journal, vol. 53, no. 2, pp. 449-463, 2015.

[27] J. Dandois, "Experimental study of transonic buffet phenomenon on a 3D swept wing," Physics of Fluids, vol. 28, no. 1, Article ID 016101, 2016.

[28] W. Zhang, C. Gao, Y. Liu, Z. Ye, and Y. Jiang, "The interaction between flutter and buffet in transonic flow," Nonlinear Dynamics, vol. 82, no. 4, pp. 1851-1865, 2015. 


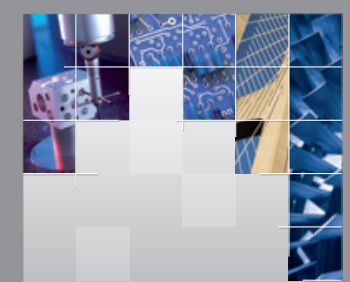

\section{Enfincering}
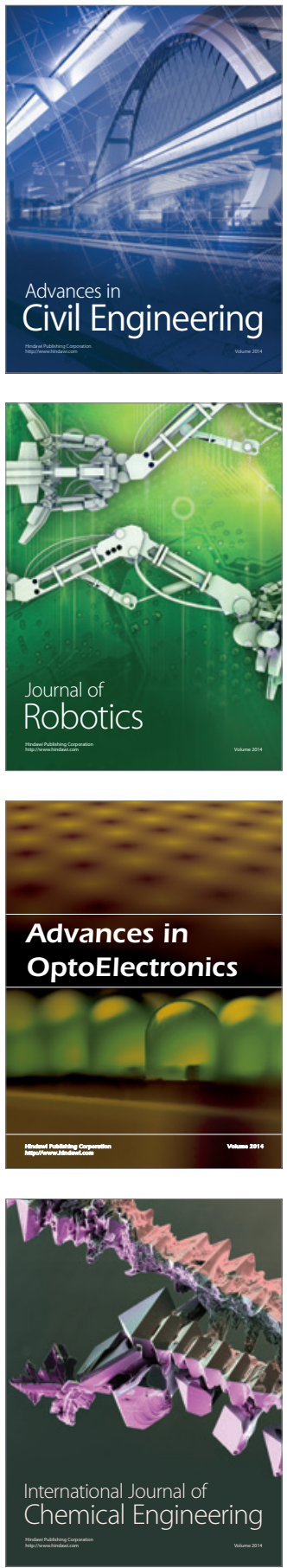

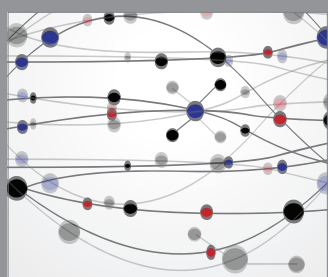

The Scientific World Journal

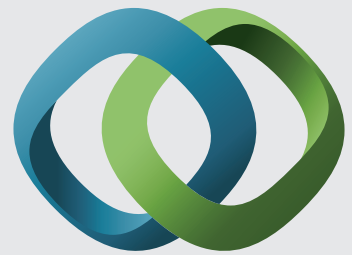

\section{Hindawi}

Submit your manuscripts at

http://www.hindawi.com
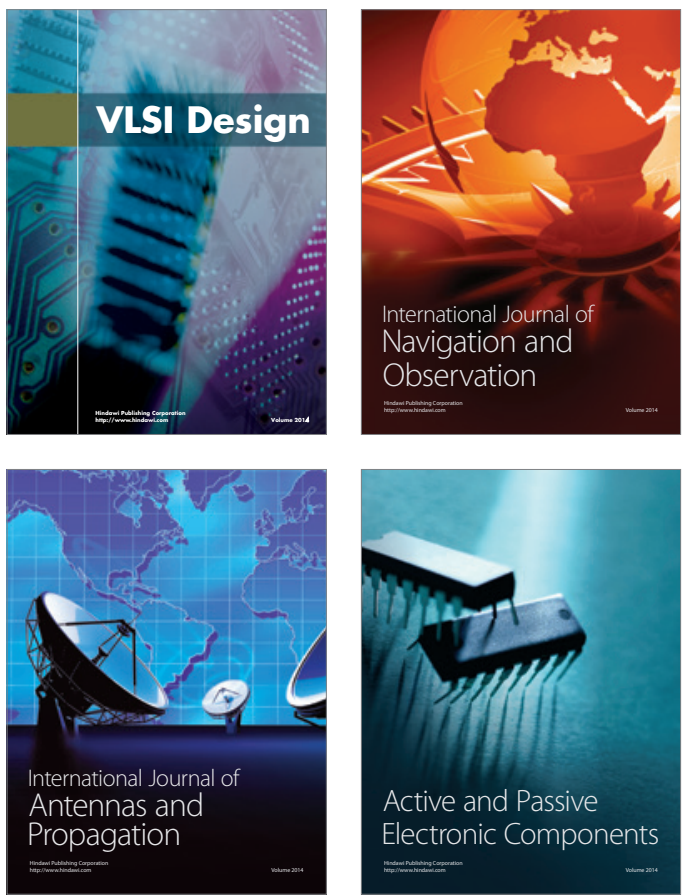
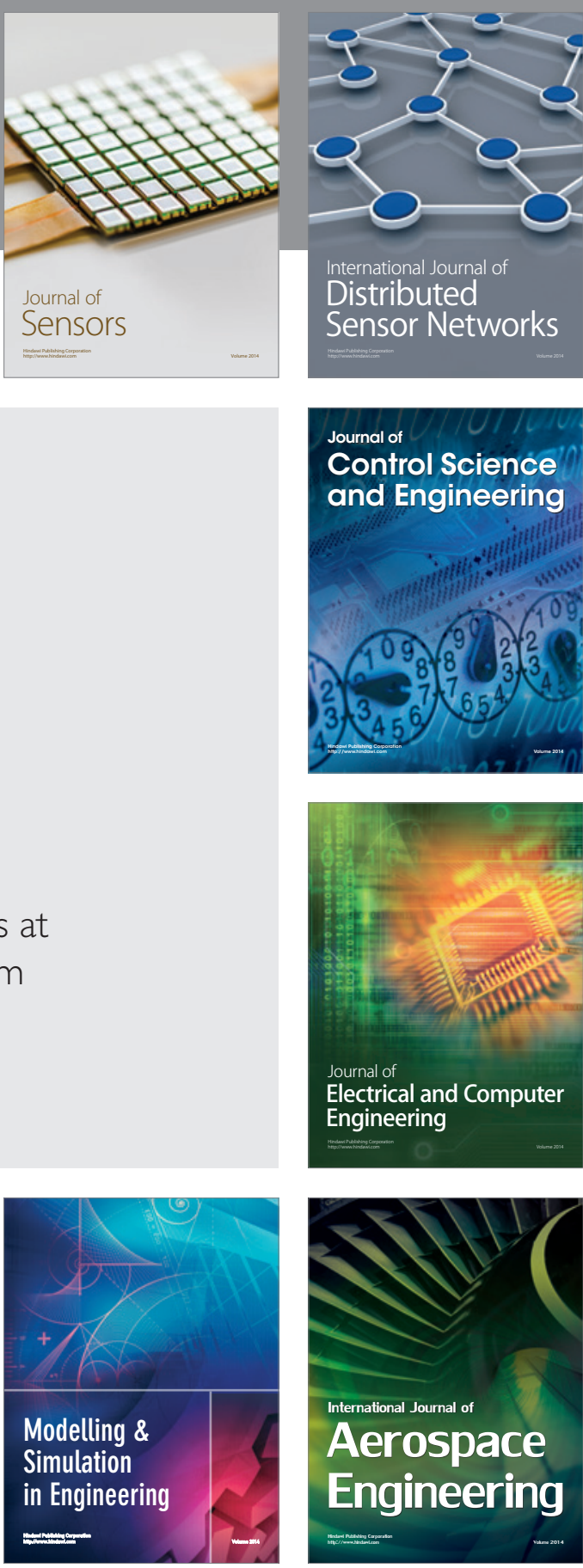

International Journal of

Distributed

Sensor Networks

Journal of

Control Science

and Engineering
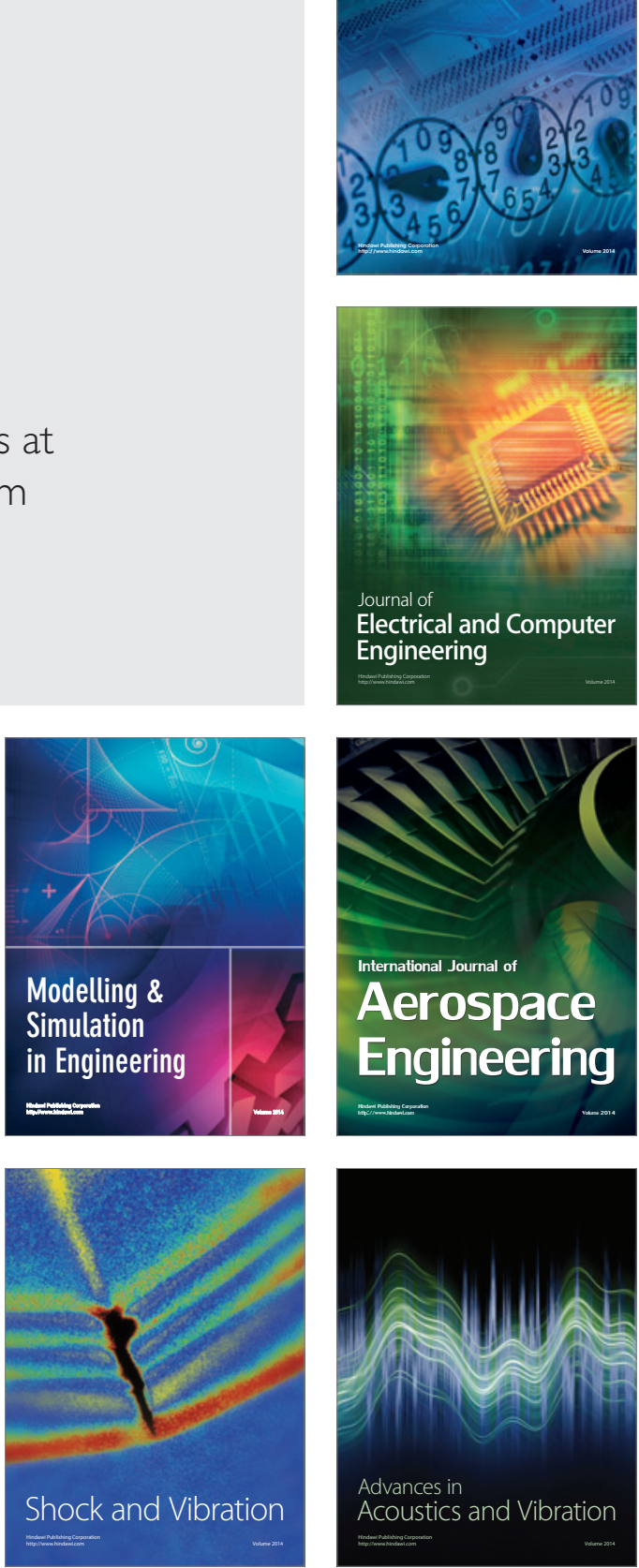